\title{
The failure of the floating cover of a vertical cylindrical tank
}

\author{
C Babiş ${ }^{1}$, O R Chivu ${ }^{1}$, A Dimitrescu ${ }^{2}$, L Dascalu ${ }^{1}$, E Niculae $^{2}$, G Iacobescu $^{1}$, A \\ Semenescu $^{3}$, O D Negoita ${ }^{4}$ and A Purcarea ${ }^{4}$ \\ ${ }^{1}$ Welding and Material Technology Department, Politehnica University of Bucharest, Romania \\ ${ }^{2}$ Theory of Mechanisms and Robots Department, Politehnica University of Bucharest, \\ Romania \\ ${ }^{3}$ Economics Engineering Department, Politehnica University of Bucharest, Romania \\ ${ }^{4}$ Faculty of Entrepreneurship, Business Engineering and Management, Politehnica University \\ of Bucharest, Romania \\ claudiubbs@gmail.com
}

\begin{abstract}
The location of oil tanks for the storage of volatile hydrocarbons could be done in geographical areas where the standard unit weight of the snow layer on the horizontal surface of the land reached $1500 \ldots 2000 \mathrm{~N} / \mathrm{m}^{2}$. The snow layer deposited on the floating cover under heavy weather conditions can cause a compressive force between 4500 and $6000 \mathrm{~N} / \mathrm{m}^{2}$. This creates problems in the operation of the tank and consequently the constructive structure of the floating cover can not bear this unitary load from the snow load, inevitably causing the damage. The capacities of the floating cover should be considered not only in terms of limitations on load-bearing considerations in general, but also in terms of the distribution of loads on the surface of the floating cover. The paper presents the aspect of the failure of a floating cover of a vertical cylindrical tank used to store liquid hydrocarbons under heavy climatic conditions.

Keywords: List oil reservoir, failure, bearing capacity.
\end{abstract}

\section{Introduction}

Vertical cylindrical and atmospheric pressure tanks are the most widespread, due to the simplicity of the materials and the execution and assembly works [1],[2],[3],[4]. These tanks are made of steel sheet, welded or riveted, of varying size, determined by the capacity. A vertical cylindrical tank with a fixed cap for liquids consists of three main parts, namely cylindrical casing, bottom and lid.

The cylindrical casing is the most important part because it receives the main load caused by the pressure exerted by the liquid stored inside. The cloak is made up of several rows of viroles, welded or riveted, whose thickness increases to the base of the tank, where the hydrostatic pressure is highest.

The cover is conical or spherical to allow drainage of rainwater or snow melting. The cover is assembled to the shell by means of a cornered steel ring. The cap must withstand permanent and accidental nominal loads, as well as the pressure variations inside, without deformation.

The bottom of the tank is made of steel sheet and consists of a central area formed by rectangular plates and a peripheral area, made up of shaped plates, for obtaining the circular shape [1].

Figure 1 shows the components of a vertical cylindrical tank with a floating lid.

It is very important that in these tanks, the sealing systems adopted must ensure a complete sealing of the working space of the tank, in case of passing over some irregularities of the casing, over welded stitches, and maintain a permanent contact, sufficiently tight, between screen or cover and cover, without the need for pushing to a large force to carry the screen or cover movement. In this regard, 
sealing systems with ring seal are used as shown in Figure 2(a) or with toroidal gasket filled with air or water, as seen in Figure 2(b).

Sealing systems with loop-shaped gaskets can also be adopted for better sealing. These can provide the simple loop seal as shown in Figure 3(a) and the double loop as shown in Figure 3(b).

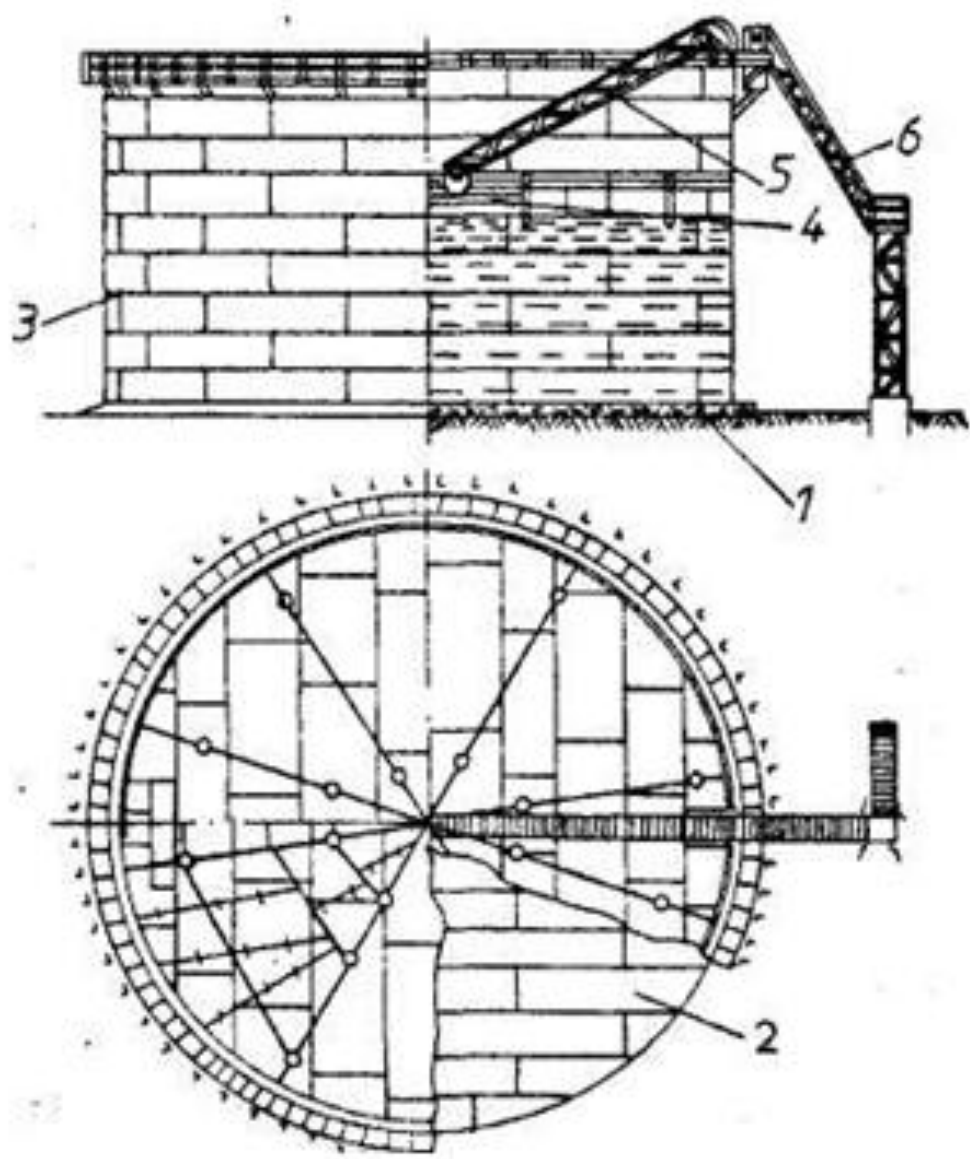

Figure 1. Overview of the vertical cylindrical tank with floating cover-funding the tank; 2- the bottom of the tank; 3-shell of the tank; 4 floating cover; 5-sliding access staircase; 6-outer access staircase.

The simple loop seal is shown in Figure 3(a) and the double loop is shown in Figure 3(b).

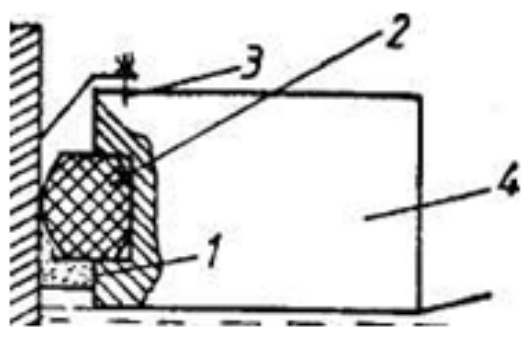

(a)

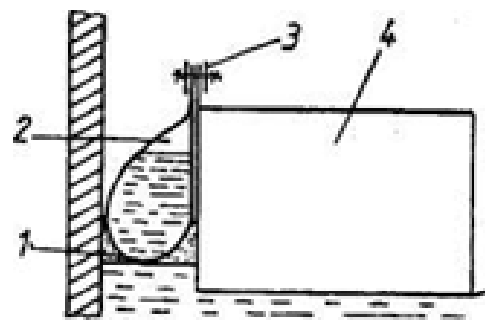

(b)

Figure 2. Sealing with ring seal and toroidal gasket

(a)-seal with-ring seal; (b)-with toroidal gasket filled with air or water

The sealing system with the deburring gasket is more efficient. 


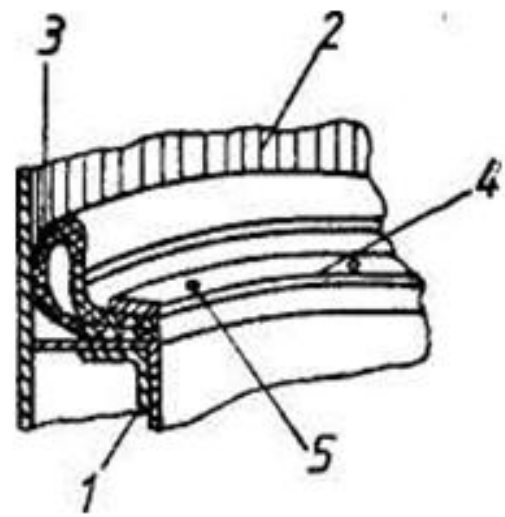

(a)

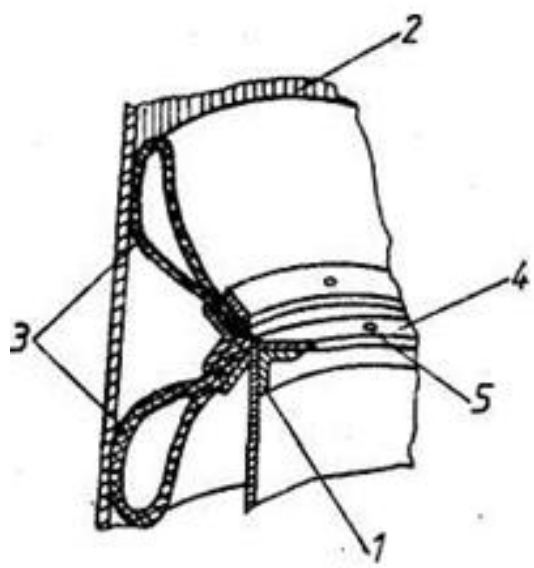

(b)

Figure 3. Sealing system with loop seal (a)-with a simple loop; (b)-double loop

\section{Experimental Research}

Experimental research refers to the floating capacities of a $5000 \mathrm{~m} 3$ vertical CVV-CP cylindrical tank used for storage of petroleum-based liquid hydrocarbons under heavy climatic conditions.

The main features of this tank are: $22800 \mathrm{~mm}$ for the cylindrical shell and $22250 \mathrm{~mm}$ for the floating cover; heights of $11940 \mathrm{~mm}$ for the cylindrical shell and $10940 \mathrm{~mm}$ at the top the floating cover, for which the useful storage capacity of the gasoline was $4540 \mathrm{~m} 3$; float cover mass $38600 \mathrm{~kg}$; type of sealing system: pontoon.

The process of storing gasoline in severe climatic conditions, with heavy snow and wind, did not delay the incidents.

The location of oil tanks for the storage of volatile hydrocarbons of the type RCV-CP in geographical areas where the standard unit weight of the snow layer on the horizontal surface of the land reaches a conventional value of $1500 \ldots 2000 \mathrm{~N} / \mathrm{m}^{2}$ in case of transition to heavy climatic conditions, the unit weight of the snow cover deposited on the floating cover [3] may be 4500-6000 N $/ \mathrm{m}^{2}$. This creates problems in the operation of the RCV-CP, the floating cover construction can not support this unitary load from snow load. The capacities of the floating cover should be considered not only in terms of limitations for load limiting/take-up considerations, but also under the aspect of the distribution of loads on the surface of the floating cover.

From the analysis according to [3] on snow accumulations on RCV-CP oil, exposed to hydrometeorological action with heavy snow and wind, the following are highlighted:

- the same RCV-CP the height of the snow cover on the floating cover is $3 \ldots 4$ times higher, sometimes even ten times higher, on the "wind" side, than on the "housed" side;

- for RCV-CP in technological storage, the height of the snow cover on the floating cover is lower than the RCV-CP that is almost empty (technologically unprocessed).

On the basis of the observations and considerations already set out above [3], the following should be noted:

- on the surface of the floating cover, the height of the snow layer is uneven, the largest amount of snow accumulates on / on the "wind" side;

- $\mathrm{RCV}-\mathrm{CP}$ in technological gasoline storage processing is less susceptible to snow accumulation on the floating cover than the same tank in standby with the floating cover in its lower position;

- The total amount of snow accumulated on the floating cover in winter may exceed several times the actual weight of the floating cover itself. 


\section{Experimental Results}

The natural fall of precipitation (snow) and wind direction favored the accumulation of a large amount of snow over that considered in the design calculation, with uneven settlement on the surface of the floating cover. This has been felt, as seen in Figures 4 and 5, in the degradation of the float cover displacement, has led to the tilting float cap tilting about an almost diametrical axis, reaching the shell, having an arrow of approximately $200 \mathrm{~mm}$ shifted by the broken prop.

The sealing system of the floating cover deteriorated approximately $50 \%$, the rubber membrane broke and the gripping accessories deteriorated.

The failure of the sealing sistem can be seen in Figure 4.

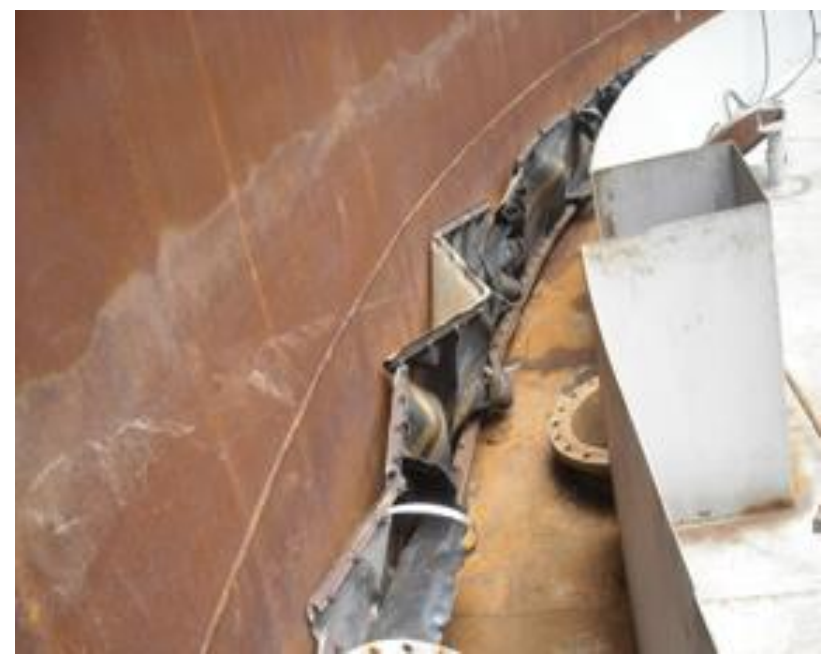

Figure 4. Failure of the sealing system

The failure of the ponton can be seen in Figure 5.

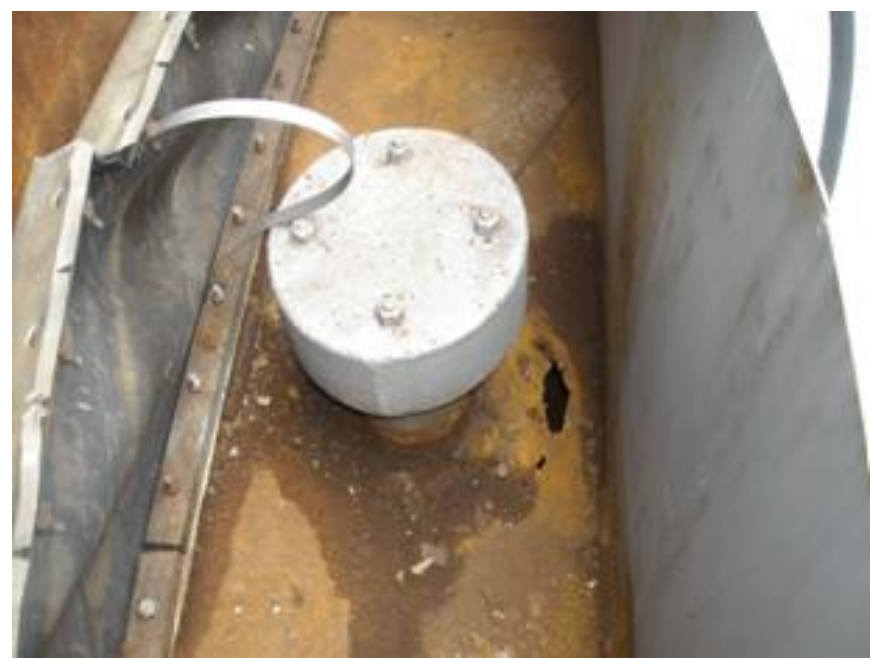

Figure 5. Failure of the pontoon

The anti-rotation DN300 and DN200 anti-drift devices have been deformed as seen in Figure 6. 
Volume 1, Issue 1, 2019

ISSN: 2668-0416

Thoth Publishing House

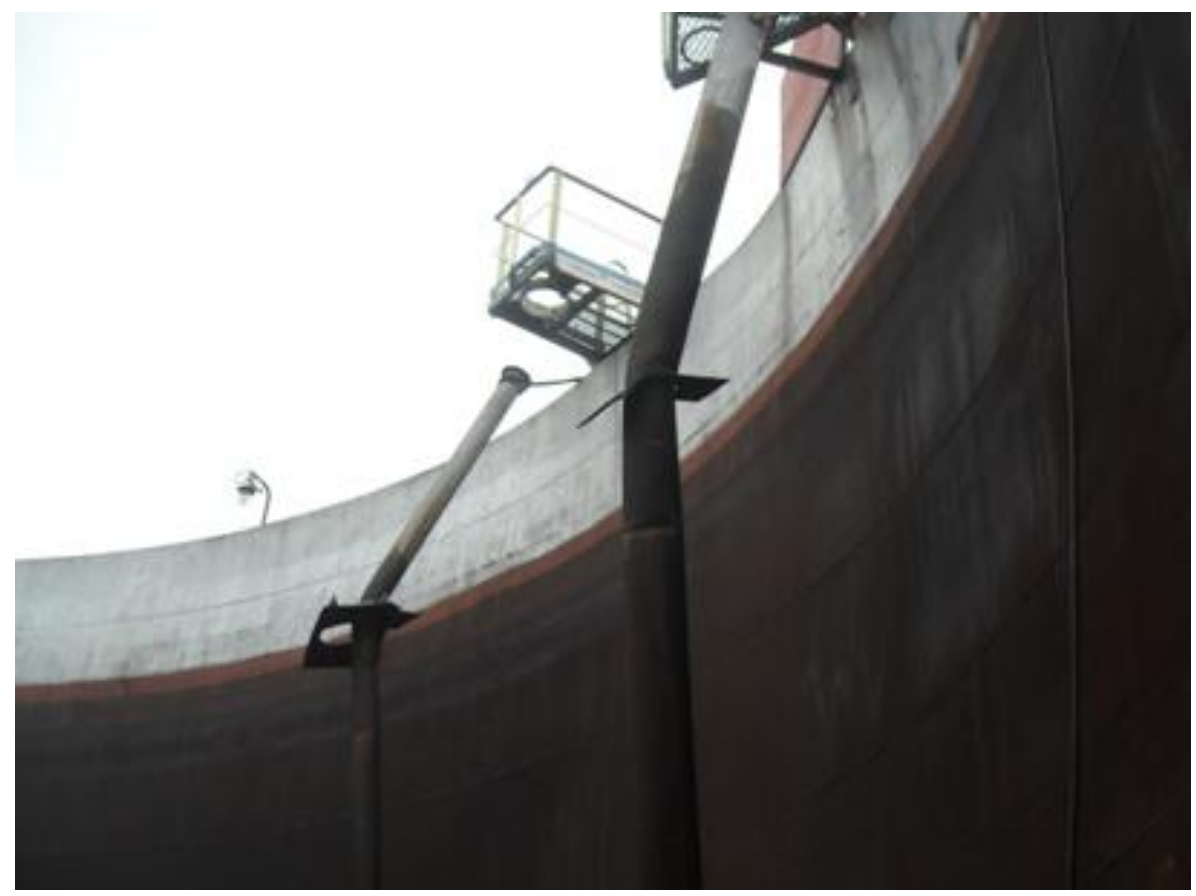

Figure 6. Failure of anti-rotation devices DN 200 and DN 300

The guide plate has been detached from the pontoons, the inner clamping welded yoke on the tank has been damaged and the bottom plate of the device antirotative was damaged, as seen in Figure 7.

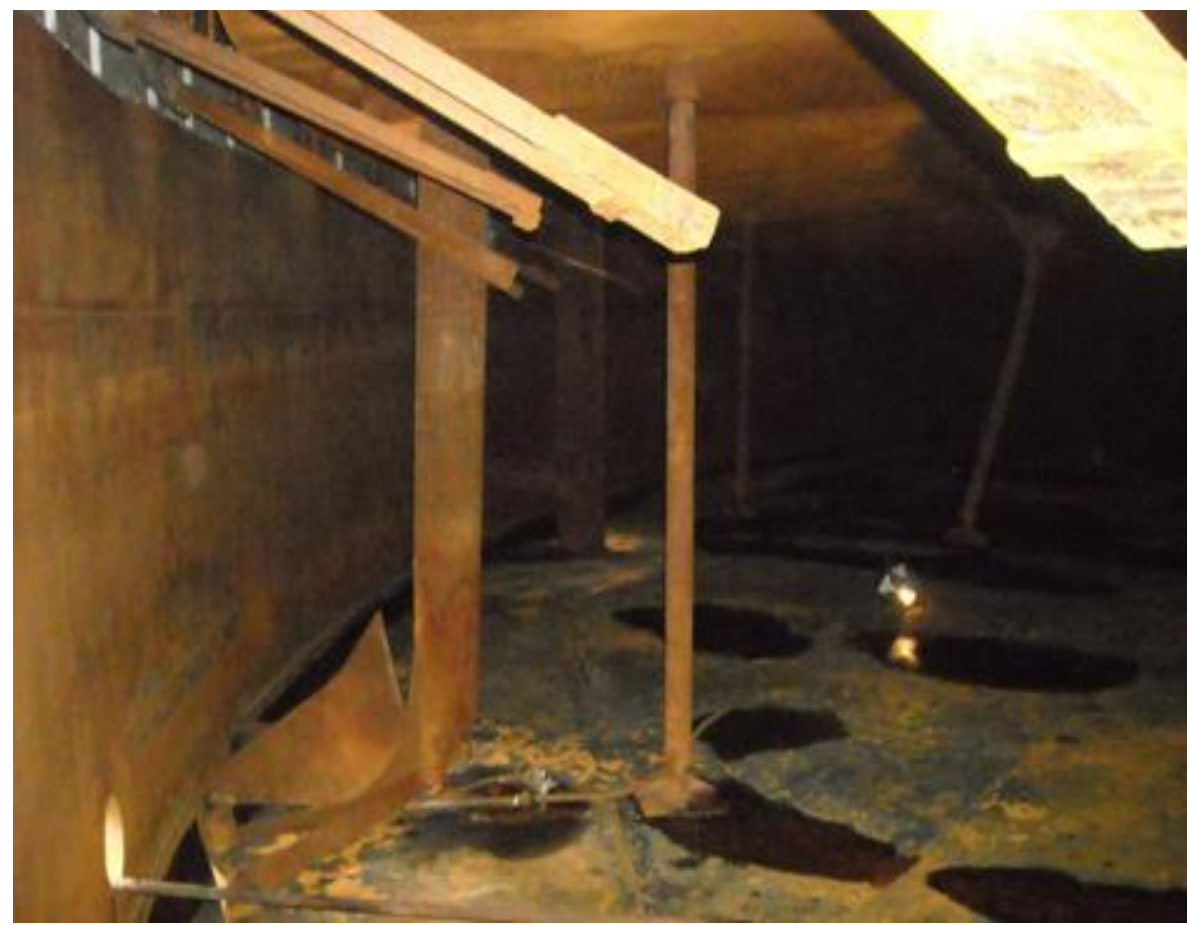

Figure 7. Failure of the bottom plate of anti-rotation devices

The support caps of the floating cover have been deformed, the pontoons and the membrane having the removed buffers, as can be seen in Figures 8 and 9. 


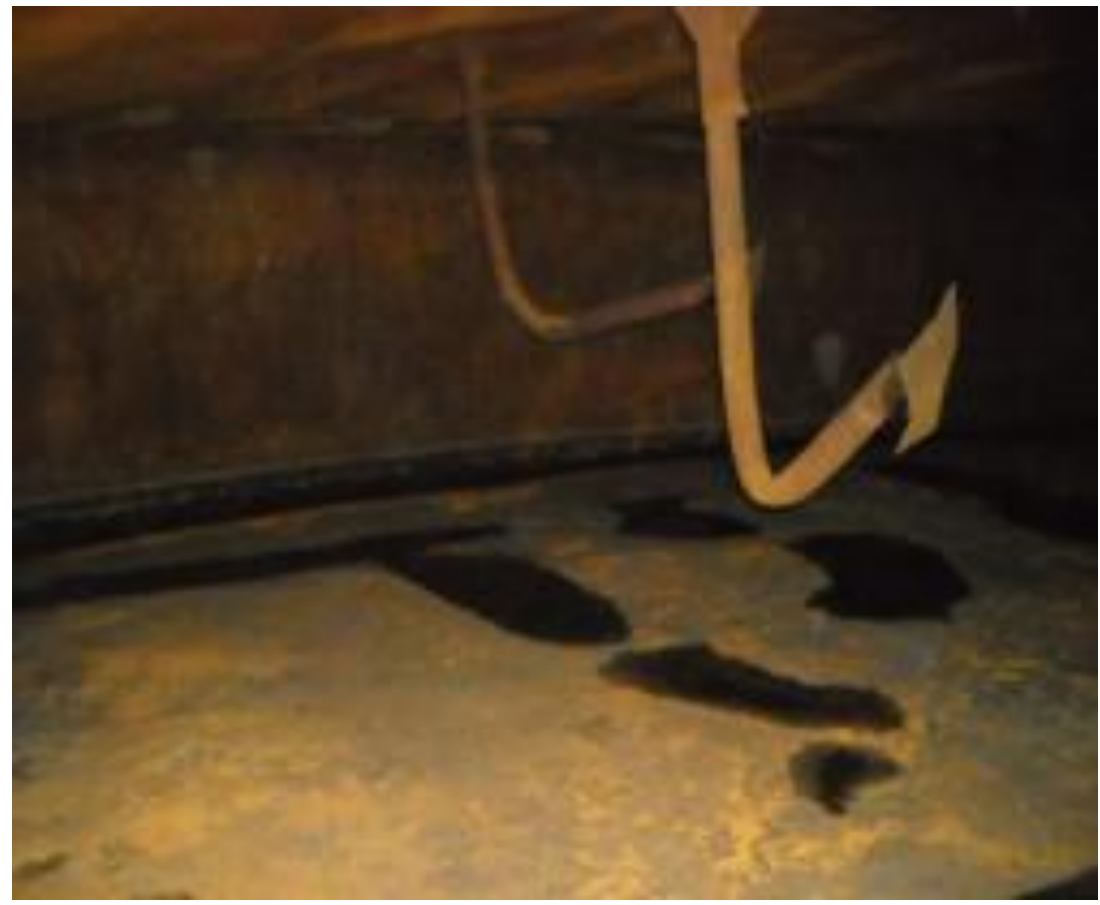

Figure 8. Failure of the floating cover pillar damaged inside

The failure of the floating cover pillar damaged on the outside can be seen in Figure 9.

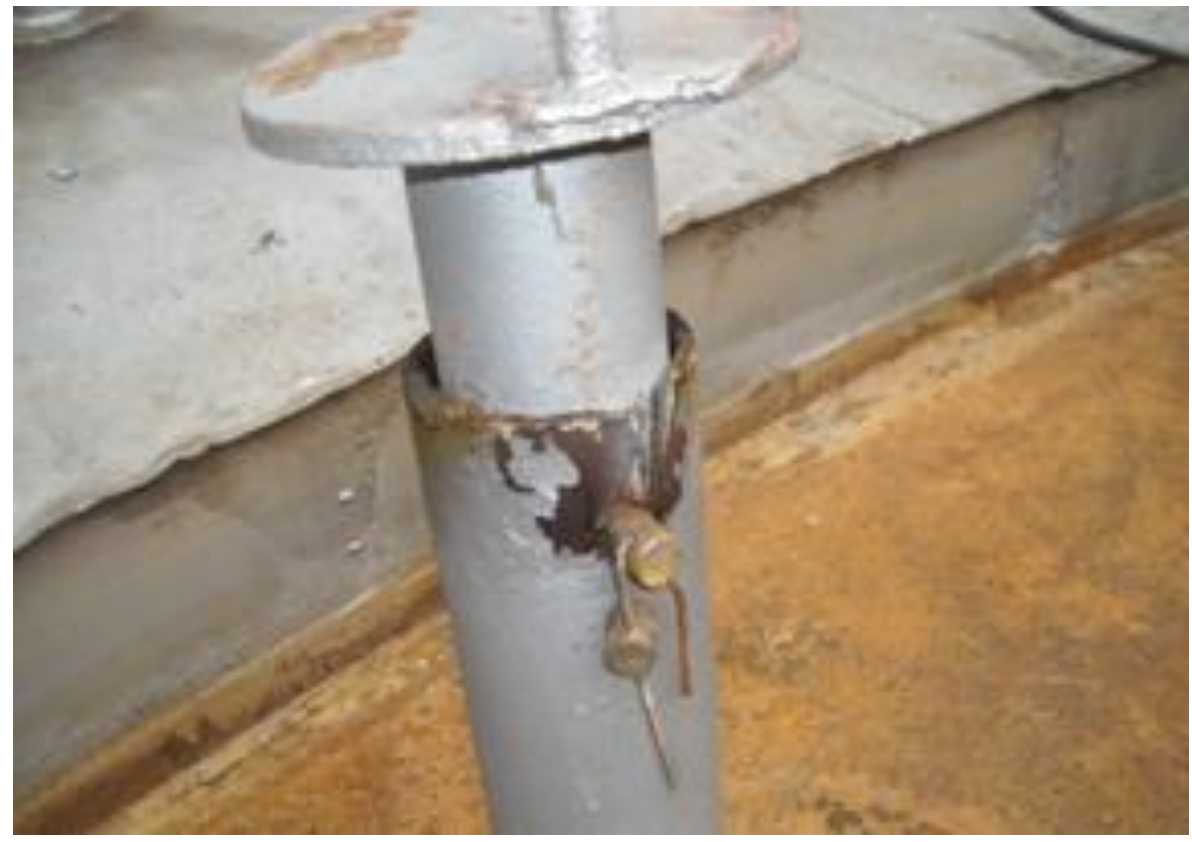

Figure 9. Failure of the floating cover pillar damaged on the outside

The cloak of the last and penultimate violin was deformed to the inside about $200 \mathrm{~mm}$ in length about $4 \mathrm{~m}$ in the area of the antirotative device, as can be seen in Figure 10.

The deformation of the cover in the area of the anti-rotation device is shown also in Figure 10. 


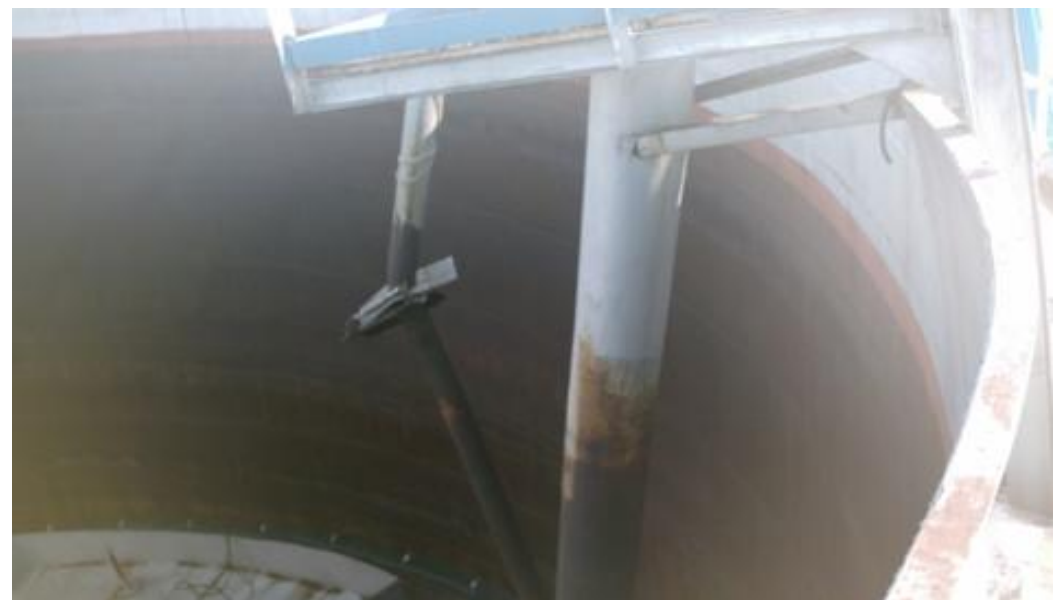

Figure 10. Deformation of the cover in the anti-rotation area

As a result of the established damages, measures were taken to prevent them. Massive snowfall due to heavy snow and wind, associated with low ambient temperatures, sometimes diminishes the reliability of the process and can drastically affect the technical or technological safety of RCV-CP floating-tanks.

The problems of snow load of the floating cover are of particular interest and it should not be forgotten that the manual removal of snow on the floating cover is neither productive nor tempting as an opportunity and would only be possible in the top most position of the floating cover.

Figure 11 illustrates [4] and schematised in principle a technological water removal system resulting from the defrosting of snow on the $\mathrm{CP}$. The water is evacuated through the hose 10 to the sewer 13 and the heating agent (steam) has a course $5 \rightarrow 6 \rightarrow 7 \rightarrow 8 \rightarrow 12$.

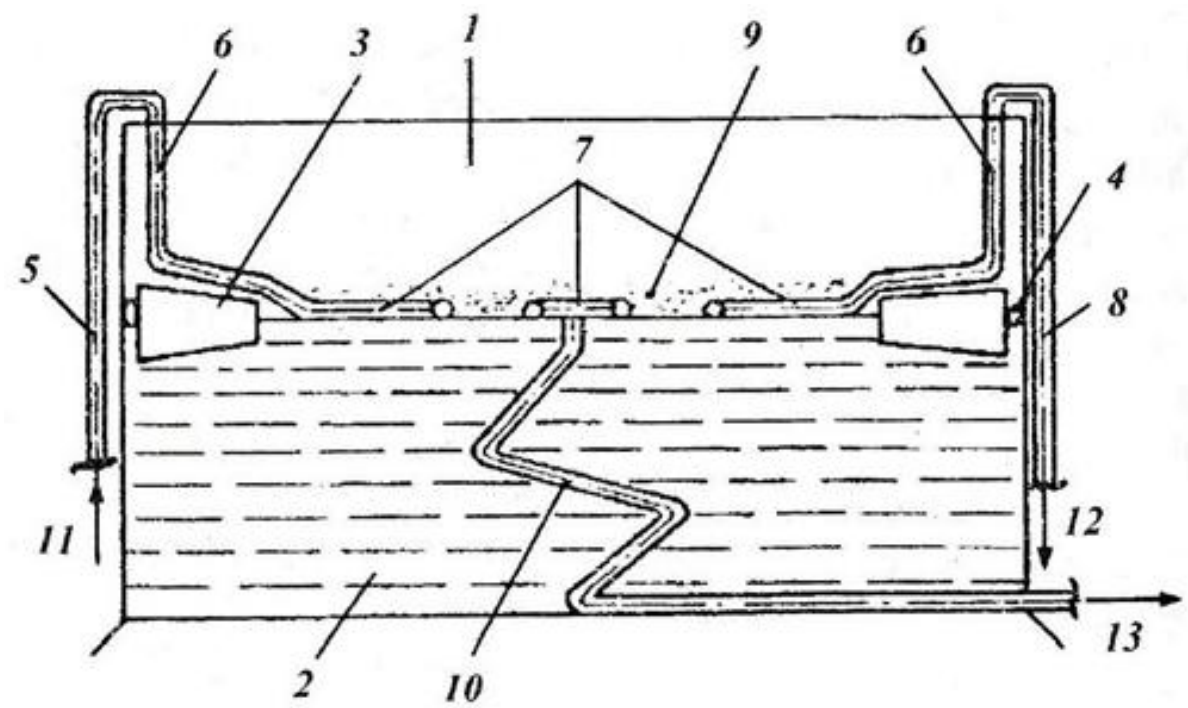

Figure 11. The principal scheme of a technological water removal system resulted from the defrosting of snow

1-RCV-CP; Stored 2-benzene; 3-floating cover (with peripheral pontoon); 4-peripheral and sealing device; 5-metallic pipe for the introduction of steam into the coil of the $\mathrm{CP}$; 6-hose reinforced; 7-tube heating coil on CP; 8-metallic duct for condensate drainage; 9 snow; 10-articulated drainage pipe; 11, 12-steam input and condensate outlet; 13 sewage water 
The following advantages are noted:

- It completely eliminates the manual actions of defrosting the CP;

- Snow removal and ice is certain in any position in RCV-CP;

- The feasibility of technological processing of gasoline storage in HPV-CP under winter conditions is considerably improved;

- The articulated pipe for the removal of water from the snow melting on the CP is permanently and completely stored in gasoline which a priori does not exclude gasoline leaks through the joints and other own components reaching the sewer (environmental pollution risk).

\section{Conclusions}

Based on the work done, the following significant aspects can be highlighted and highlighted:

- At the vertical cylindrical tanks with floating lid exposed to the front wind action, the height of the snow cover on the floating cover is smaller than the vertical cylindrical tank with sheltered floating cover;

- In the vertical cylindrical tank in technological storage, the height of the snow layer on the floating cover is smaller than the vertical cylindrical tank with floating cover, which are almost empty and therefore technologically unprocessed;

- On the surface of the floating cover, the height of the snow layer is uneven;

- To reduce the height of the snow cover on the floating cover, it is reasonable to place the vertical cylindrical tanks with floating petroleum cap on a single row, which is frontal means that is, perpendicular to the predominant conventional winter wind direction and to the distance between the reservoirs dictated by the reasons for the decrease of snow accumulations on the floating cover.

\section{References}

[1] Monika O., Peter P.,Milan U.,Fracture mechanism differences created by fatigue and impact test, Materialstoday Proceedings, vol. 4/issue 3, pp 5921-5924, 2017

[2] Zhao-Ling W, Heng X,Direct modeling of multi-axial fatigue failure for metals, International Journal of Solids and Structures, pp 216-231, 2017

[3] Pavel, A., Siguranţa în funcţionare a utilajelor petrochimice, Editura Tehnică, vol 3, pp 5-365, 1988

[4] Armando L., Rama I., José A., Carlos A., Branco G., Fatigue behaviour of T welded joints rehabilitated by tungsten inert gas and plasma dressig, Materials and Design, vol 32, pp 4705-4713, 2011 